\title{
SUICIDE ASSOCIATED WITH RISK FACTORS IN PATIENTS SUFFERING FROM DEPRESSION
}

Sher Ayub Dawar ${ }^{1}$, Abdul Waris $^{2}$, Hina Niaz ${ }^{3}$, Zahida Ayub $^{4}$, Nazia Qureshi ${ }^{5}$

\section{ABSTRACT:}

\section{OBJECTIVES:}

The purpose of this study was to assess suicide and their relationship with risk factors i.e. degree of hopelessness, severity of depression and suicidal ideations.

\section{METHODOLOGY:}

It was a cross sectional study conducted in Psychiatry unit Khyber Teaching Hospital Peshawar. The total sample of this study was forty-eight admitted patients. Those patients were included in the study that scored moderate to high in Hamilton Depression Rating Scale (HDRS), Hopelessness Scale and Reasons for Living Inventory (RLI). The collected data were analysed using SPSS version 22.

\section{RESULTS:}

Study showed that reasons for living as well as the subscales of reasons for living inventory i.e. responsibility towards family, hope of improvement and surviving and coping beliefs have significant inverse correlation with score on Hopelessness Scale and suicidal ideations. The score on subscale religious beliefs had significant correlation only with score on hopelessness. Married individuals' responses were different on total reasons for living to a significant extent. The patients with past psychiatric history had significantly greater fear of suicide. The three different social groups did not differ to a significant extent in scoring on reasons for living.

\section{CONCLUSION:}

The reasons for living as a whole and some of the subscales of Reasons for Living Inventory have significant inverse relationship with suicidal risk factors showing the modulatory effect of these reasons on suicidal risk. Moreover, these reasons are not equally distributed among some of the sociodemographic and clinical groups.

KEYWORDS: Hopelessness, Suicide, Fear, Religious Belief, Psychiatry

How to cite this article:

Dawar AS, Waris A, Niaz H, Ayub Z, Qureshi N. Suicide A ssociated with Risk Factors in Patients Suffering from Depression. J Gandhara Med Dent Sci. 2020; 7(1): 30-38

https://doi.org/10.37762/jgmds.7-1.101 


\section{Correspondence}

${ }^{1}$ Sher Ayub Dawar, Senior Registrar, Department of Psychiatry, Khyber Teaching Hospital, Peshawar.

Cell\# +92-333-9368720

Email: drsherayub@gmail.com

${ }^{2}$ Resident Cardiologist, Lady Reading

Hospital, Peshawar.

${ }^{3}$ Consultant gynecologist, Khyber Teaching

Hospital, Peshawar.

${ }^{4}$ Clinical Psychologist, Pakistan institute of

Prosthetic and Orthotic Sciences,

Peshawar.

${ }^{5}$ Clinical Psychologist, Khyber Teaching

Hospital, Peshawar.

\section{INTRODUCTION:}

Depressive illness is the fourth leading cause of the global burden of disease $(\mathrm{GBD})^{1}$. Moreover, depressed people are at high risk of suicide. More than $50 \%$ of suicides are attributed to an episode of major depression $^{2,}{ }^{3}$. In the past it was a commonly held belief that suicide was the problem of western industrialized countries but now it is a major health problem even in developing countries ${ }^{4,5}$. A study has reported that 5000 people attempted suicide between 1997-1999 in Pakistan. Despite this fact it is a poorly studied subject in our country ${ }^{4,6}$. There is a lot of research on identifying various risk factors for suicidal behavior throughout the world. But the factors that protect an individual from acting on suicidal urges have little been studied. This is even though the lower rates of suicides have mainly been attributed to the protective influence of religion and family ${ }^{7-9}$. Research has shown that patients who struggle with their suicidal urges have reasons that help them in protection from acting on their suicidal thoughts. These reasons represent various socio-cultural and religious factors and a scale has been designed to assess these reasons ${ }^{10}$. Hopelessness, suicidal ideations and degree of depression are the main determinants of suicidal risk $^{7}$. The main focus of preventive efforts, against suicide and deliberate selfharm, has been to address the risk factors. Augmenting the protective factors against the suicide can also be helpful in preventing the suicide and deliberate self-harm. The nature of various protective factors and their relationship with the risk factors can help to identify the strategies for effective interventions in reducing suicide and deliberate self-harm. The present study aims at finding the relationship between the risk factors and the protective factors mentioned above. In addition, the proportion of these factors in different sociodemographic and clinical groups will also be studied.

\section{METHODOLOGY:}

A cross sectional study conducted in psychiatry unit of Khyber Teaching Hospital Peshawar (May-November 2018). 48 patients were selected for this study through systematic sampling technique. The inclusion criteria of the patients were having greater than 17 score on HAM-D, age range of 15 to 65 years and the ability to communicate properly. All those patients who either did not give 
informed consent or their depressive illnesses were secondary to organic and other psychiatric disorders like schizophrenia or substance abuse were excluded. Semi structured interview was conducted for associated clinical characteristics and diagnosis of depression according to the ICD-10 criteria. The questionnaires used in this study are Hamilton Depression Rating Scale (HDRS) for rating of severity of depression $^{10}$, Beck Hopelessness Scale (BHS) for measurement of degree of hopelessness ${ }^{11}$ and Reasons for Living Inventory (RLI). $\mathrm{RLI}$ was used to assess the various reasons given by the patients for not acting on suicidal urges. The data was analyzed with the help of SPSS version 22. Spearman's correlation analysis was used to find out strength and direction of correlation of total scoring on reasons for living and scores on subscales of RLI with degree of hopelessness, suicidal ideations and score on HDRS. F-test was administered for comparisons of mean scores of groups like married and single individuals on total reasons for living and subscales of RLI like responsibility towards family and religious beliefs.

\section{RESULTS:}

The analysis of reasons for living given by the patients showed that responsibility towards family was considered as the most significant protective factor against suicide both in males and females. This was closely followed by the religious beliefs.

Table 1: Protective Factors and their Mean Score

\begin{tabular}{|l|c|c|}
\hline \multicolumn{1}{|c|}{ Reasons } & Mean & Standard Deviation \\
\hline Responsibility Towards Family & 8.08 & 2.81 \\
\hline Religious Beliefs & 7.28 & 2.35 \\
\hline Hope of Improvement & 5.78 & 2.12 \\
\hline Survival and Coping Beliefs & 5.62 & 1.78 \\
\hline Fear of Social Disapproval & 5.18 & 1.60 \\
\hline Child Related Concern & 4.94 & 3.97 \\
\hline Fear of Suicide & 3.88 & 1.45 \\
\hline
\end{tabular}


Total score on reasons for living was inversely correlated with score of hopelessness and suicidal ideations to a statistically significant extent i.e. at significance level $<0.01$ and 0.05 , while with score on HDRS their relation was negative but not statistically significant. Among the subscales of $\mathrm{RLI}$, responsibility towards family, hope of improvement and surviving and coping beliefs also had statistically significant correlation with hopelessness and suicidal ideations. Religious beliefs had significant inverse correlation with hopelessness only $(r=-.411, P<0.01)$. The three subscales i.e. fear of social disapproval, child related concern and fear of suicide did not have any significant inverse correlation with scores of hopelessness, HDRS and suicidal ideations.

Table 2: Correlations of The Scores of All Reasons as a Whole and The Subscales of RLI with Scores on HDRS, Hopelessness and Suicidal Ideation

\begin{tabular}{|l|c|c|c|}
\hline \multicolumn{1}{|c|}{ Factors } & $\begin{array}{c}\text { Score of } \\
\text { Hopelessness }\end{array}$ & $\begin{array}{c}\text { Score of Suicidal } \\
\text { Ideations }\end{array}$ & HDRS Score \\
\hline $\begin{array}{l}\text { Total Scores on Reasons by Every } \\
\text { Individual }\end{array}$ & -.435 & $-.329^{*}$ & -.123 \\
\hline Responsibility Towards Family & $-.287^{*}$ & $-.329^{*}$ & .029 \\
\hline Religious Beliefs & & -.278 & -.085 \\
\hline Hope & $-.411^{* *}$ & -.407 & -.107 \\
\hline Surviving and Coping Beliefs & $-.579^{* *}$ & -.470 & -.026 \\
\hline Fear of Social Disapproval & $-.381^{* *}$ & -.140 & -.014 \\
\hline Child Related Concern & -.225 & -.240 & -.083 \\
\hline Fear of Suicide & -.023 & -.203 & \\
\hline$* * 0.01$ & -.198 & & \\
$*<0.05$ & & & \\
\hline
\end{tabular}

NOTE: Values are of Spearman's correlation coefficient. 
There was no statistically significant difference on various subscales of RLI between married and single subjects. However, there is statistically significant difference between the two groups on total RLI scores $(D f=1, f=6.383, P<0.05)$ and on the subscale of child related concern $(D f=1, f=105.681, P<0.001)$ as shown in Table 3. Table 4 shows the individuals having past psychiatric history differed to a statistically significant extent only in scores on subscale, fear of suicide $(\mathrm{Df}=1$, $f=4.067, P<0.05)$.

Table 3: Significance of Difference Between Married and Single Individuals in Scoring on Reasons for Living as a Whole and The Subscales of RLI

\begin{tabular}{|l|c|c|c|c|c|}
\hline \multicolumn{1}{|c|}{ Factors } & $\begin{array}{c}\text { Mean Score of } \\
\text { Unmarried } \\
\text { Patients }\end{array}$ & $\begin{array}{c}\text { Mean Score of } \\
\text { Married Patients }\end{array}$ & Df. & F. & Sig. \\
\hline All Reasons for Living & 34.56 & 42.94 & 1 & 6.383 & 0.015 \\
\hline $\begin{array}{l}\text { Responsibility Towards } \\
\text { Family }\end{array}$ & 8.00 & 8.12 & 1 & 0.019 & 0.892 \\
\hline Religious Beliefs & 6.75 & 7.53 & 1 & 1.204 & 0.278 \\
\hline Hope of Improvement & 5.50 & 5.91 & 1 & 0.405 & 0.528 \\
\hline Surviving and Coping Beliefs & 6.06 & 5.41 & 1 & 1.463 & 0.232 \\
\hline Fear of Social Disapproval & 3.69 & 4.41 & 1 & 2.289 & 0.137 \\
\hline Child Related Concern & 0.19 & 7.18 & 1 & 105.681 & 0.000 \\
\hline Fear of Suicide & 3.87 & 3.88 & 1 & 0.000 & 0.987 \\
\hline
\end{tabular}

Table 4: Comparison of patients score with and without psychiatry history

\begin{tabular}{|l|c|c|c|c|c|}
\hline \multicolumn{1}{|c|}{ Factors } & $\begin{array}{c}\text { Mean Score of } \\
\text { Patients with } \\
\text { Past Psychiatry } \\
\text { History }\end{array}$ & $\begin{array}{c}\text { Mean Score of } \\
\text { Patients without } \\
\text { Past Psychiatry } \\
\text { History }\end{array}$ & Df. & F. & Sig. \\
\hline All Reasons for Living & 42.91 & 39.51 & 1 & .741 & .394 \\
\hline $\begin{array}{l}\text { Responsibility Towards } \\
\text { Family }\end{array}$ & 7.82 & 8.15 & 1 & .121 & .730 \\
\hline
\end{tabular}




\begin{tabular}{|l|c|c|c|c|c|}
\hline Religious Beliefs & 7.45 & 7.23 & 1 & .076 & .783 \\
\hline Hope of Improvement & 6.55 & 5.56 & 1 & 1.868 & .178 \\
\hline Surviving and Coping Beliefs & 5.91 & 5.54 & 1 & .366 & .548 \\
\hline Fear of Social Disapproval & 4.64 & 4.05 & 1 & 1.151 & .289 \\
\hline Child Related Concern & 5.91 & 4.67 & 1 & .837 & .365 \\
\hline Fear of Suicide & 4.64 & 3.67 & 1 & 4.067 & .049 \\
\hline
\end{tabular}

\section{DISCUSSION:}

Although suicide has not been adequately addressed in local literature ${ }^{4}$, several studies in our country as well as in other countries of the region specifically India, have addressed related issues. Nunni and Mani, for example, explored psycho demographic profile of suicidal ideations; Srivastavasa and Kulshreshta found low positive correlation between severity of depression and suicide; and Narang et al, showed that mood disorder was the most common psychiatric illness in suicidal patients ${ }^{13,14,15}$. On an extensive search into the local literature and Extra Med, we could not find a study on similar subjects. Therefore the findings of the present study could only be compared with those of the studies conducted mostly in U.S and U.K. These comparisons will have inherent limitations of widely different socio-cultural settings. This study aimed at finding relationship between risk factors and protective factors of suicide. It was found that the total score on all reasons for living had significant inverse correlation with scores on hopelessness and suicidal ideations. These findings are consistent with the findings of Malone et $\mathrm{al}^{7}{ }^{7}$ and Mann et $\mathrm{al}^{16}{ }^{16}$. Both studies reported very significant negative correlation between scores of all reasons for living and hopelessness $^{7,16}$. These findings support the possible modulatory effect of the reasons for living on suicidal risk. An inverse relationship between the two sets of factors suggests that the reasons for living given by the patients have a protective influence. These reasons seem to counteract the influence of risk factors. The study also attempted to analyze correlations of scores on different subscales of RLI with scores on hopelessness, HDRS and suicidal ideations to know the relative importance of these subscales or factors. We found that all these factors at least had negative correlation with all the three risk factors separately. However, scores on two protective factors i.e. responsibility towards family and surviving and coping beliefs had significant inverse correlation with scores on hopelessness and suicidal ideations. Score on religious beliefs had significant inverse correlation 
only with hopelessness. The literature on the whole seems to support the hypothesis that religion and family cohesion are associated with lower scores on suicidal ideations ${ }^{17-20}$. Therefore, it appears that the responsibility towards family and the religious beliefs are two main antagonists of hopelessness and suicidal ideations. This is also evident from the fact that these two factors were rated as the two commonest reasons for living. It has been acknowledged that religious beliefs and some socio-cultural traditions do influence the extent and severity of suicidal mortality and mental health as a whole. Various religious and socio-cultural traditions, in the Asians and other ethnic minorities, seem to play a protective role in mental health. This might partially explain the lower rates of suicide reported in Bangladeshis and Pakistanis when compared with other ethnic groups ${ }^{21}$, 22. But this aspect has been largely ignored in cross-cultural research ${ }^{23}$, 24 . There was a significant difference between married and single individuals on scores of total reasons for living. This was accounted mainly for by the score of married patients on child related concern. As previous literature shows that single people commit suicide more than married individuals $^{24}$. It is possible that child related concern might partially be responsible for the relatively greater protection for married individuals against suicidal acts. This, however, needs to be studied further in studies incorporating proper controls. The difference in scoring on total reasons for living was not significant between the two age groups i.e. above and below 40 years. It is an interesting finding and needs to be replicated in an older adult population. Subjects with history of a psychiatric illness scored significantly higher on the subscale for fear of suicide. But there was no statistically significant difference in scoring on total reasons for living. This finding is interesting. It appears that individuals who had past psychiatric history of depression developed fear of suicide. Moreover, the study has also shown that groups based on available support i.e. poor, fair and excellent varied to a significant extent in scoring on hopelessness but did not vary significantly in scoring on HDRS and total reason for living. This finding suggests that level of social support is not a determinant of RLI. So, it appears that reasons for living constitute an independent cognitive schema, not influenced by difference in age and level of support available to the individuals. However, this hypothesis needs to be tested in further studies. The score on HDRS did not bear significant correlation with reasons for living. Malone et al, ${ }^{7}$ has shown that score on Beck Depression Inventory has significant inverse relationship with score on reasons for living. In the literature, the difference has been attributed to the fact that HDRS measures subjective depression while Beck Depression Inventory measures objective depression $^{7,}{ }^{16}$. This study is an attempt to explore the different dimensions of various reasons for not acting on suicidal ideas and urges. 


\section{CONCLUSION:}

The present study has the following practical implications; Assessment of Reasons for living should be considered as important as that of risk factors while assessing suicidal risk in depressed patients. It has been demonstrated that depressed and suicidal patients have negative cognitive sets. While reasons for living seem to have modulatory effect on suicidal risk. These reasons may possibly be used in psychotherapeutic interventions like cognitive behavioral therapy (CBT) and rational emotive behavioral therapy (REBT) for depressed and suicidal patients. These may help to modify distorted cognitive schema and challenge negative thoughts of a depressed patient. Cross-cultural research regarding the protective factors against suicide will be of utmost importance in highlighting the positive value of different sociocultural and religious traditions.

\section{LIMITATIONS:}

One of the limitations of the study includes a relatively small sample size. This was due to fact that we have limited resources. The study had no funding. Another limitation is lack of a proper control group. Further research is needed on larger samples while incorporating proper controls.

\section{REFERENCES:}

1. Rockett IR. Counting suicides and making suicide count as a public health problem.
2. Shekhani SS, Perveen S, Akbar K, Bachani S, Khan MM. Suicide and deliberate self-harm in Pakistan: a scoping review. BMC psychiatry. 2018 Dec 1;18(1):44.

3. Gibbons RD, Brown $\mathrm{CH}$, Hur $\mathrm{K}$, Marcus SM, Bhaumik DK, Erkens JA, Herings RM, Mann JJ. Early evidence on the effects of regulators" suicidality warnings on SSRI prescriptions and suicide in children and adolescents. American Journal of $\quad 2007$ Sep;164(9):1356-63.

4. Naveed S, Qadir T, Afzaal T, Waqas A. Suicide and its legal implications in Pakistan: a literature review. Cureus. 2017 Sep;9(9).

5. Barber RM, Fullman N, Sorensen RJ, Bollyky T, McKee M, Nolte E, Abajobir AA, Abate $\mathrm{KH}$, Abbafati $\mathrm{C}$, Abbas KM, Abd-Allah F. Healthcare Access and Quality Index based on mortality from causes amenable to personal health care in 195 countries and territories, 1990-2015: a novel analysis from the Global Burden of Disease Study 2015. The Lancet. 2017 Jul 15;390(10091):231-66.

6. Abidi M, Zia W, Waqas M. Deliberate self-harm: A local perspective. J Pak Psychiatry Soc. 2010; 7:67.

7. O'Connor RC, Nock MK. The psychology of suicidal behaviour. The Lancet Psychiatry. 2014 Jun 1;1(1):73-85.

8. Javed MA. Religion, spirituality and mental health. Pak J Med Sci. 2000; 16:61-3.

9. Qureshi NA, Alduraihem RA, Aldosari SM, Alhabeeb AA. Epidemiological Trend, Risk Factors, 
Prevention and Treatment Strategies of Self-directed Violent Behavior: A Critical Appraisal of Relevant Literature. Journal of Advances in Medicine and Medical Research. 2020 Feb 11:51-70.

10. Hamilton M. A rating scale for depression. J Neurol Neurosurg Psychiatry. 1960;23(1):56-62.

11. Beck AT, Weismann A, Lester L. The measurement of pessimism: the hopeless- ness scale. J Consult Clin Psychol. 1974;42:861-5.

12. Van Orden KA, Witte TK, Cukrowicz KC, Braithwaite SR, Selby EA, Joiner Jr TE. The interpersonal theory of suicide. Psychological review. 2010 Apr;117(2):575.

13. Radhakrishnan R, Andrade C. Suicide: an Indian perspective. Indian journal of psychiatry. 2012 Oct:54(4):304.

14. Vijayakumar L, Umamaheswari C, Ali ZS, Devaraj P, Kesavan K. Intervention for suicide attempters: A randomized controlled study. Indian journal of psychiatry. 2011 Jul;53(3):244.

15. Gandhi A, Luyckx K, Maitra S, Claes L. Non-suicidal self-injury and other self-directed violent behaviors in India: A review of definitions and research. Asian journal of psychiatry. 2016 Aug 1;22:196-201.

16. Nock MK, Borges G, Bromet EJ, Cha CB, Kessler RC, Lee S. Suicide and suicidal behavior. Epidemiologic reviews. 2008 Nov 1;30(1):133-54.

17. Arria AM, O'Grady KE, Caldeira KM, Vincent KB, Wilcox HC, Wish ED. Suicide ideation among college students: A multivariate analysis. Archives of Suicide Research. 2009 Jul 16;13(3):230-46.
18. Mahdi A, Pourahmad A, Zarghamfard M, Qasemi S. Analysis of urban health from a social capital perspective in Iranian religious cities: Qom. Spatial Information Research. 2016 Dec 1;24(6):689-99.

19. Smith TB, McCullough ME, Poll J. Religiousness and depression: evidence for a main effect and the moderating influence of stressful life events. Psychological bulletin. 2003 Jul;129(4):614.

20. Pargament KI, Falb MD, Ano GG, Wachholtz AB. The religious dimension of coping: Advances in theory, research, and practice.

21. Bhopal RS, Humphry RW, Fischbacher CM. Changes in cardiovascular risk factors in relation to increasing ethnic inequalities in cardiovascular mortality: comparison of cross-sectional data in the Health Surveys for England 1999 and 2004. BMJ open. 2013 Sep 1;3(9).

22. Shaw RJ, Atkin K, Bécares L, Albor CB, Stafford M, Kiernan KE, Nazroo JY, Wilkinson RG, Pickett KE. Impact of ethnic density on adult mental disorders: narrative review. The British Journal of Psychiatry. 2012 Jul;201(1):11-9.

23. Javed MA. Programs of mental health and policies in South Asia: Origin and current status. InMental health in South Asia: Ethics, resources, programs and legislation 2015 (pp. 81-94). Springer, Dordrecht.

24. Shahid M, Hyder AA. Deliberate selfharm and suicide: a review from Pakistan. International journal of injury control and safety promotion. 2008 Dec 1;15(4):233-41. 


\section{CONTRIBUTORS}

1. Sher Ayub Dawar - Concept \& Design; Data Analysis/Interpretation; Drafting Manuscript; Critical Revision; Supervision; Final Approval

2. Abdul Waris - Data Acquisition; Data Analysis/Interpretation; Drafting Manuscript; Final Approval

3. Hina Niaz - Concept \& Design; Data Acquisition; Data Analysis/Interpretation; Critical Revision; Supervision; Final Approval

4. Zahida Ayub - Data Acquisition; Data Analysis/Interpretation; Drafting Manuscript; Critical Revision; Final Approval

5. Nazia Qureshi - Data Acquisition; Data Analysis/Interpretation; Drafting Manuscript; Final Approval

ICENSE: JGMDS publishes its articles under a Creative Commons Attribution Non-Commercial Share-Alike license (CC-BY-NC-SA 4.0). COPYRIGHTS: Authors retain the rights without any restrictions to freely download, print, share and disseminate the article for any lawful purpose. It includes scholarly networks such as Research Gate, Google Scholar, LinkedIn, Academia.edu, Twitter, and other academic or professional networking sites 